\title{
Construction and Validation of a Women's Autonomy Measurement Scale with Reference to Utilization of Maternal Health Care Services in Nepal
}

Tulsi Ram Bhandari, ${ }^{1}$ Ganesh Dangal, ${ }^{2}$ P Sankara Sarma, ${ }^{1}$ V Raman Kutty ${ }^{1}$

\begin{abstract}
'Department of Public Health, School of Health and Allied Sciences, Pokhara University, Kaski, Nepal, 'Achutha Menon Centre for Health Science Studies, Sree Chitra Tirunal Institute for Medical Sciences and Technology, Trivandrum, Kerala India, ${ }^{2}$ Department of Obstetrics and Gynaecology, Kathmandu Model Hospital, Kathmandu, Nepal.
\end{abstract}

\section{ABSTRACT}

Introduction: Women's autonomy is one of the predictors of maternal health care service utilization. This study aimed to construct and validate a scale for measuring women's autonomy with relevance to developing countries.

Methods: We conducted a study for construction and validation of a scale in Rupandehi and further validated in Kapilvastu districts of Nepal. Initially, we administered a 24-item preliminary scale and finalized a 23-item scale using psychometric tests. After defining the construct of women's autonomy, we pooled 194 items and selected 24 items to develop a preliminary scale. The scale development process followed different steps i.e. definition of construct, generation of items pool, pretesting, analysis of psychometric test and further validation.

Results: The new scale was strongly supported by Cronbach's Alpha value (0.84), test-retest Pearson correlation (0.87), average content validity ratio (0.8) and overall agreement- Kappa value of the items $(0.83)$ whereas all values were found satisfactory. From factor analysis, we selected 23 items for the final scale which show good convergent and discriminant validity. From preliminary draft, we removed one item; the remaining 23 items were loaded in five factors. All five factors had single loading items by suppressing absolute coefficient value less than 0.45 and average coefficient was more than 0.60 of each factor. Similarly, the factors and loaded items had good convergent and discriminant validity which further showed strong measurement capacity of the scale.

Conclusions: The new scale is a reliable tool for assessing women's autonomy in developing countries. We recommend for further use and validation of the scale for ensuring the measurement capacity.

Keywords: maternal health care; scale construction and validation; women's autonomy measurement.

\section{INTRODUCTION}

Autonomy is a multidimensional concept and difficult to quantify. ${ }^{1}$ However, increasing women's autonomy is a well-documented strategy for improving the utilization of maternal health care services in developing countries. $^{2}$ Women who have greater autonomy in decision-making, and in physical and financial resources are able to seek health care services for themselves and their children, and are able to make fertility decision independently. ${ }^{3-6}$ Similarly, socio-economic factors are

Correspondence: Dr. Tulsi Ram Bhandari, Achutha Menon Centre for Health Science Studies, Sree Chitra Tirunal Institute for Medical Sciences and Technology Trivandrum, Kerala, India, Email: tulsib2004@ gmail.com , Phone: +977-9851178182/ +91-9605657941. 
Bhandari et al. Construction and Validation of a Women's Autonomy Measurement Scale with Reference to Utilization of Maternal ...

positively associated with their autonomy in decisionmaking and seeking maternal health care services..$^{2,7}$

In Nepal, previous studies show that women's education, occupational status and spousal support for seeking care associated positively with women's autonomy. ${ }^{3,8}$ In most South East Asian countries, women have inferior position and less power for making household decision and seeking health care services. ${ }^{8}$ It further indicates that the poor women's autonomy at household level where women still do not access of required maternal health care services without prior permission of either their husbands or senior members of their family.

Despite the importance of women's autonomy in utilization of maternal health care services, very few studies used specific validated measurement scales to assess the association between women's autonomy and utilization of maternal health care services in Nepal. To minimize the literature gaps, this study aimed to construct and validate a measurement scale for assessing the women's autonomy with relevance to utilization of maternal health care services in the context of Nepal and other developing countries.

\section{METHODS}

We conducted a population based cross-sectional studies in Rupandehi district of Nepal. Sree Chitra Tirunal Institute for Medical Sciences and Technology, Trivandrum, Kerala, India granted ethical clearance for this study. After intensive literature reviewing and consulting with experts, we prepared a preliminary draft of the scale that consisted of 24 items. The study was conducted in llaka (subdivision of district) number eleven of Rupandehi district which consists of four village development committees (VDC); out of four, we selected two VDCs randomly using lottery method. We followed the convenience sampling technique and administered the scale to 250 married women of reproductive age considering the ratio $(1: 10)$ of items and respondents.

We further executed next study for further validation of the scale in Kapilvastu district. The target population comprised reproductive age women who had full term delivery within a year and completed their postnatal period. Sample size was fixed based on the proportion of skilled care at birth (15.92\%) of Kapilvastu district, 9 with assumed design effect $=2$ and non-response rate $=20 \%$ using online OpenEpi statistics software. ${ }^{10} \mathrm{We}$ selected ten VDCs out of 76 VDCs of the district using simple random sampling (lottery) method. The final number of women at VDC was fixed proportionately based on the population of each VDC. We interviewed 500 women from 10 VDCs of the district using a structured interview schedule and the autonomy measurement scale constructed by ourselves. For identifying the respondents in each village, we consulted the local people to identify the center of village. We went to the center and started data collection in a randomly chosen direction. We continued household visit in the clock-wise direction until obtaining the required number of respondents using convenience sampling.

\section{Steps of Scale Construction and Validation}

Definition of construct: Assessment of women's autonomy and its influence on maternal health care is a complex task. ${ }^{11}$ More recently, it is defined as women's enacted ability to influence decisions, control economic resources and move freely. ${ }^{8,12}$ Higher women's autonomy is positively associated with the greater utilization of maternal health care services. In most of the developing countries, women's decisionmaking autonomy, movement autonomy and financial autonomy influence the utilization of maternal health care and other health services. ${ }^{13}$ We focused on these three dimensions of the women's autonomy which have higher weightage in women's autonomy measurement particularly in the developing countries. We defined women's autonomy as a capacity of women to control over decision-making, financial and physical resources, and mobility.

\section{Generation of items pool}

We reviewed literature intensively for generating the items pool. First, we pooled 194 items from different studies and removed all duplicate items. After review by two experts, we finalized 24 items which were associated with financial autonomy, movement autonomy and decision-making autonomy of the women particularly in the context of developing countries.

All items were categorized into three areas i.e. decision making autonomy, movement autonomy and financial autonomy of women. Items were scored on a threepoint Likert-type scale with the lowest score as zero and the highest score as two. For decision-making autonomy, the options from highest to lowest scores were: independent, joint and dependent. Similarly, for movement autonomy and financial autonomy, the options from highest to lowest scores were: Never, sometimes and always. The total score consisted of the sum of individual items with higher score would reflect the better women's autonomy.

Pretest of scale: We translated English-version of scale into Nepali-version and pre-tested in Parroha VDC of Rupandehi district. We interviewed 20 married women of 14 to 49 years old considering at least one respondent from each five-year interval of the age groups. After completion of interviews, we held a meeting to analyze the data and build up consensus on the findings of 
Bhandari et al. Construction and Validation of a Women's Autonomy Measurement Scale with Reference to Utilization of Maternal ...

pretest. Major changes were not required, only some items needed clarity. We simplified and modified some items accordingly.

\section{Reliability and validity measurement}

We conducted a study among 250 reproductive age women for scale construction and validation in Saljhandi and Rudrapur VDCs in Rupandehi district. Out of total respondents, $211(84.4 \%)$ were from Saljhandi VDC. Enumerators visited respondents at their home using convenience sampling method. All respondents were explained about objective of the study and requested for their participation in research. We obtained informed consent, and conducted face-to-face interview and recorded essential information. The response rate was $99.28 \%$, seven respondents showed reluctance take part in the study.

We administered same draft in other two subsamples to estimate the test-retest reliability. Similarly, for calculating the validity ratio and index, the scale was supplied to the 22 subject experts for their comments on contents of the scale. The scale was supplied to the experts by email and returned in the same manner. The response rate of the emailed scale was $68.18 \%$.

\section{Psychometric analysis of the scale}

Reliability and validity are two fundamental characteristics of measurement. Reliability refers to the consistency or precision in measurement and validity refers to how well a scale measures what it is purported to measure. ${ }^{14} \mathrm{We}$ applied various reliability and validity tests to guarantee the strength of the scale for measuring women's autonomy.

Internal consistency: We calculated correlation $(r)$ by Cronbach's Alpha (ㅁ) methods and assessed the inter correlation of each domain.

Test-retest reliability: For establishing the consistency across the items, we performed test-retest method in subsample (50 women) in one month interval and calculated Pearson's correlation ( $r$ ). The correlation ( $r$ ) 0.6 and above was considered acceptable for assessing the cross items consistency. ${ }^{14}$

Face validity: The draft was administered to ten people at community and primary health care facilities. The selected respondents assessed the scale reflecting what it was intended to measure. The scale was modified and finalized based on feedback of the piloting. Face validity is a subjective assessment of scale $;^{15}$ thus we considered all the subjective ideas of the participants during analysis of the data.

Content validity: For assuring the content of the scale, we circulated preliminary draft to public health and reproductive health experts and modified based on their feedbacks. The content validity was also assessed by testing the level of agreement among experts. We circulated the same draft to a next subsample of the experts. The subsample consisted of university's teachers, researchers and public health workers. Items were scored on a three-point Likert-type scale with scoring of two (essential), one (useful not essential) and zero (not necessary). First, we calculated content validity ratio and content validity index and second, using above subsample, we merged scoring range from three groups to two groups- 'essential' and 'useful not essential' into one group and 'not necessary' into other group to calculate the multirater Kappa. We used online Multirater Kappa Calculator to compute the multirater Kappa. ${ }^{16}$

\section{Further validation of scale}

Factor analysis: Factor analysis is used to confirm a smaller number of domains from a large number of observed items. Researchers may use factor analysis for a wide purpose; one of the most prevalent uses of factor analysis is to support the validity of newly constructed scale whether it measures what it is intended to measure or not. ${ }^{17}$ We used exploratory factors analysis (EFA) for the dimensionality assessment and items reduction of the proposed scale. The EFA was intended to identify the underlying factors, compute communalities, distinguish items loading together, as well as identify the strong and weak factors of the scale. It is a new scale; so we assumed all the factors uncorrelated and applied the principal component factor extraction method with the Eigenvalues greater than one followed by the orthogonal rotation method Varimax. ${ }^{18}$

Construct validity: convergent and discriminant validity

Convergent and discriminant validity are subtypes of construct validity. Theoretically, convergent and discriminant validity should measure similarity and dissimilarity of the constructs respectively. For ensuring the construct validity of the scale, both validities should be assessed simultaneously. ${ }^{19,20}$ We used rotated component matrix table of factor analysis to test convergent and discriminant validity of the scale. We assessed correlation coefficient of the items within a factor to ensure the convergent validity and loading of factors to ensure the discriminant validity of the scale.

\section{RESULTS}

Internal consistency: Cronbach's Alpha value was 0.84 . Correlation among individual items showed that all items of the scale correlated positively. The Cronbach's Alpha (Table 1), and item statistics and total items statistics (Table 2) showed good internal consistency of the items in scale. 
Bhandari et al. Construction and Validation of a Women's Autonomy Measurement Scale with Reference to Utilization of Maternal ...

\begin{tabular}{|lclllll|}
\hline \multicolumn{2}{|l}{ Table 1. Internal consistency. } & & & \\
\hline Sample size & Mean & Variance & $\begin{array}{l}\text { Std. } \\
\text { deviation }\end{array}$ & $\begin{array}{l}\text { No. of } \\
\text { items }\end{array}$ & $\begin{array}{l}\text { Cronbach's } \\
\text { Alpha }\end{array}$ & $\begin{array}{l}\text { Cronbach's Alpha based } \\
\text { on standardized items }\end{array}$ \\
250 & 35.31 & 24.97 & 5.0 & 24 & 0.84 & 0.85 \\
\hline
\end{tabular}

Table 2. Item and total items statistics of scale.

Items statistics

Items

Mean SD

\section{Scale mean}

if item deleted
Total items statistics

$\begin{array}{cc}\text { Scale } & \text { Corrected } \\ \text { variance if } & \text { item-total } \\ \text { Item deleted } & \text { correlation }\end{array}$

Cronbach's Alpha if item deleted

\begin{tabular}{|c|c|c|c|c|c|c|}
\hline What food should be cooked & 1.98 & 0.15 & 33.33 & 24.58 & 0.24 & 0.84 \\
\hline $\begin{array}{l}\text { Daily household expenditure/ } \\
\text { purchase }\end{array}$ & 1.77 & 0.43 & 33.54 & 22.68 & 0.52 & 0.83 \\
\hline Children's clothes and food & 1.87 & 0.35 & 33.44 & 23.51 & 0.40 & 0.84 \\
\hline Children's education & 1.09 & 0.29 & 34.22 & 24.63 & 0.09 & 0.84 \\
\hline $\begin{array}{l}\text { Children's and females' health } \\
\text { care and medicine }\end{array}$ & 1.83 & 0.38 & 33.48 & 23.74 & 0.29 & 0.84 \\
\hline Inviting and hosting guests & 1.42 & 0.53 & 33.89 & 21.87 & 0.57 & 0.83 \\
\hline Use of contraceptives & 1.00 & 0.14 & 34.30 & 24.65 & 0.21 & 0.84 \\
\hline Having baby/another baby & 1.00 & 0.14 & 34.30 & 24.63 & 0.23 & 0.84 \\
\hline $\begin{array}{l}\text { Purchase major goods in } \\
\text { household such as land, } \\
\text { house, computer, TV }\end{array}$ & 1.08 & 0.35 & 34.23 & 23.41 & 0.43 & 0.83 \\
\hline $\begin{array}{l}\text { Being a member of public } \\
\text { institutions/organizations }\end{array}$ & 1.82 & 0.41 & 33.48 & 23.01 & 0.45 & 0.83 \\
\hline $\begin{array}{l}\text { Go outside the house/ } \\
\text { compound }\end{array}$ & 1.62 & 0.49 & 33.69 & 22.14 & 0.56 & 0.83 \\
\hline Go marketing/shopping & 1.95 & 0.22 & 33.36 & 24.11 & 0.37 & 0.84 \\
\hline $\begin{array}{l}\text { Go to hospital/health care } \\
\text { facility }\end{array}$ & 1.88 & 0.34 & 33.43 & 23.39 & 0.45 & 0.83 \\
\hline Go to children's school & 1.92 & 0.28 & 33.39 & 24.10 & 0.29 & 0.84 \\
\hline $\begin{array}{l}\text { Visit to natal family or } \\
\text { relative/s' house }\end{array}$ & 1.06 & 0.41 & 34.24 & 23.05 & 0.45 & 0.83 \\
\hline Visit to friend/s' house & 1.12 & 0.42 & 34.19 & 22.90 & 0.47 & 0.83 \\
\hline $\begin{array}{l}\text { Go to public places/ } \\
\text { programmes such as temple, } \\
\text { church, other religious places, } \\
\text { public programmes }\end{array}$ & 1.85 & 0.37 & 33.46 & 23.32 & 0.42 & 0.83 \\
\hline $\begin{array}{l}\text { Work outside the house for } \\
\text { income }\end{array}$ & 1.50 & 0.53 & 33.80 & 23.02 & 0.33 & 0.84 \\
\hline $\begin{array}{l}\text { Spend money for household } \\
\text { affairs }\end{array}$ & 1.87 & 0.35 & 33.44 & 23.20 & 0.49 & 0.83 \\
\hline $\begin{array}{l}\text { Lend/spend money as per } \\
\text { personal need and interest }\end{array}$ & 1.57 & 0.53 & 33.74 & 22.10 & 0.51 & 0.83 \\
\hline
\end{tabular}


Bhandari et al. Construction and Validation of a Women's Autonomy Measurement Scale with Reference to Utilization of Maternal ...

\begin{tabular}{|lcccccc|}
$\begin{array}{l}\text { Saving money for your future } \\
\text { use }\end{array}$ & 0.69 & 0.89 & 34.62 & 19.85 & 0.55 & 0.83 \\
$\begin{array}{l}\text { Handle separate bank account } \\
\text { Own and control personal }\end{array}$ & 0.70 & 0.88 & 34.61 & 19.84 & 0.55 & 0.83 \\
$\begin{array}{l}\text { property } \\
\text { Give money or goods to natal } \\
\text { family }\end{array}$ & 1.48 & 0.51 & 33.82 & 22.88 & 0.38 & 0.84 \\
\hline
\end{tabular}

Test-retest reliability: We calculated Pearson's correlation $(r)$ of the total score of observation at two times and obtained $r=0.87$. The correlation coefficient value 0.6 and above is considered acceptable for assessing the cross items consistency. ${ }^{14,15}$ The descriptive statistics and the correlation showed the good consistency across the items (Table 3).

\begin{tabular}{|llrl|}
\hline \multicolumn{3}{|l|}{ Table 3. Descriptive statistics and correlation of two } \\
repeated measurements $(\mathbf{n}=\mathbf{5 0}$ ).
\end{tabular}

\begin{tabular}{|c|c|c|c|c|c|c|c|c|c|c|c|c|c|c|c|c|c|}
\hline \multirow[t]{2}{*}{ Items } & \multicolumn{15}{|c|}{ Raters } & \multirow[t]{2}{*}{ No. of agreements } & \multirow[t]{2}{*}{$\mathrm{CVR}^{*}$} \\
\hline & 1 & 2 & 3 & 4 & 5 & 6 & 7 & 7 & 9 & 10 & 11 & 12 & 13 & 14 & 15 & & \\
\hline 1 & $x$ & $x$ & - & $\times$ & $x$ & $x$ & $x$ & $x$ & $x$ & $\times$ & $\times$ & $x$ & - & $x$ & $x$ & 13 & 0.7 \\
\hline 2 & $\times$ & $\times$ & $x$ & $\times$ & $\times$ & $x$ & $x$ & $\times$ & $\times$ & $\times$ & $\times$ & $\times$ & - & $\times$ & $\times$ & 14 & 0.9 \\
\hline 3 & $\times$ & $\times$ & $x$ & $\times$ & $x$ & $x$ & $\times$ & $\times$ & $x$ & $\times$ & $\times$ & $x$ & $\times$ & $x$ & $x$ & 15 & 1.0 \\
\hline 4 & $\times$ & $\times$ & $x$ & $\times$ & $\times$ & $x$ & $x$ & $\times$ & $\times$ & $\times$ & $\times$ & $x$ & $\times$ & $\times$ & $\times$ & 15 & 1.0 \\
\hline 5 & $\times$ & $\times$ & $x$ & $\times$ & $x$ & $x$ & $\times$ & $\times$ & $x$ & $\times$ & $\times$ & $\times$ & $\times$ & $\times$ & $x$ & 15 & 1.0 \\
\hline 6 & $\times$ & $\times$ & $x$ & $\times$ & $\times$ & - & - & $\times$ & $\times$ & $\times$ & $\times$ & $\times$ & $\times$ & $\times$ & - & 12 & 0.6 \\
\hline 7 & $\times$ & $\times$ & $x$ & $\times$ & $x$ & $x$ & $\times$ & $\times$ & $x$ & $\times$ & $\times$ & $\times$ & $\times$ & $\times$ & $x$ & 15 & 1.0 \\
\hline 8 & $\times$ & $x$ & $x$ & $\times$ & $\times$ & $x$ & $x$ & $\times$ & $\times$ & $\times$ & $\times$ & $\times$ & $\times$ & $x$ & $\times$ & 15 & 1.0 \\
\hline 9 & $\times$ & $x$ & $x$ & $\times$ & $x$ & - & $x$ & $\times$ & $x$ & $x$ & $\times$ & $\times$ & $x$ & $x$ & $x$ & 14 & 0.9 \\
\hline 10 & $\times$ & $x$ & $x$ & $\times$ & $\times$ & $x$ & - & $x$ & $\times$ & $\times$ & $\times$ & $\times$ & $\times$ & $x$ & $x$ & 14 & 0.9 \\
\hline 11 & $x$ & $x$ & $x$ & $x$ & $x$ & $x$ & - & $x$ & $x$ & $x$ & - & $\times$ & - & $x$ & $x$ & 12 & 0.6 \\
\hline 12 & $\times$ & $\times$ & $\times$ & $\times$ & $\times$ & $\times$ & - & $\times$ & $\times$ & $\times$ & $\times$ & $\times$ & - & $x$ & $\times$ & 13 & 0.7 \\
\hline 13 & $\times$ & $\times$ & $x$ & $\times$ & $x$ & $x$ & $x$ & $\times$ & $x$ & $\times$ & $\times$ & $\times$ & $\times$ & $\times$ & $x$ & 15 & 1.0 \\
\hline 14 & $\times$ & $x$ & $\times$ & $\times$ & $\times$ & $\times$ & $x$ & $\times$ & $\times$ & $\times$ & $\times$ & $\times$ & - & $x$ & $x$ & 14 & 0.9 \\
\hline 15 & $\times$ & $x$ & $x$ & $\times$ & $x$ & $x$ & - & $\times$ & $x$ & $\times$ & $x$ & $\times$ & $x$ & $x$ & $x$ & 14 & 0.9 \\
\hline 16 & $\times$ & $x$ & $\times$ & $\times$ & $\times$ & $\times$ & - & - & $\times$ & $\times$ & $x$ & $\times$ & - & $x$ & $x$ & 12 & 0.6 \\
\hline 17 & $\times$ & $\times$ & $x$ & - & $x$ & $x$ & - & $\times$ & $x$ & $\times$ & $\times$ & $\times$ & - & $x$ & $x$ & 12 & 0.6 \\
\hline 18 & $\times$ & $x$ & $\times$ & $\times$ & $\times$ & $\times$ & - & $\times$ & $\times$ & $x$ & $x$ & $\times$ & $\times$ & $x$ & $x$ & 14 & 0.9 \\
\hline 19 & $\times$ & $\times$ & $\times$ & $\times$ & $x$ & $x$ & - & $\times$ & $x$ & $x$ & $x$ & - & - & $x$ & $x$ & 12 & 0.6 \\
\hline 20 & $\times$ & $\times$ & $\times$ & $\times$ & $x$ & $x$ & $x$ & $\times$ & $x$ & $x$ & $\times$ & $\times$ & $\times$ & $\times$ & - & 14 & 0.9 \\
\hline 21 & $x$ & $\times$ & $\times$ & $\times$ & $x$ & $x$ & - & $\times$ & $x$ & $\times$ & $\times$ & $\times$ & - & $\times$ & $x$ & 13 & 0.7 \\
\hline 22 & $\times$ & $\times$ & $x$ & $\times$ & $x$ & $\times$ & - & $x$ & $x$ & $x$ & $\times$ & $\times$ & $x$ & $x$ & $x$ & 14 & 0.9 \\
\hline 23 & $\times$ & $\times$ & $\times$ & $\times$ & $x$ & $\times$ & - & $x$ & $x$ & $x$ & $\times$ & - & $x$ & $x$ & $x$ & 13 & 0.7 \\
\hline \multirow[t]{2}{*}{24} & $x$ & $x$ & $\times$ & $\times$ & $x$ & - & - & - & $x$ & $\times$ & $\times$ & - & $x$ & $\times$ & $x$ & 11 & 0.5 \\
\hline & & & & & & & & & & & & & & \multicolumn{3}{|c|}{ Average content validity ratio } & 0.8 \\
\hline
\end{tabular}


Face validity: We circulated preliminary draft to ten primary health care workers and community volunteers. We collected written as well as verbal comments on the scale and modified some items considering their feedback. The scale was assessed considering what it is intended to measure on women's autonomy. Face validity is also regarded as a subjective assessment of scale, so we also considered the subjective ideas of the participants throughout the data analysis.

Content validity: Average content validity ratio and overall agreement among raters (Kappa value) of the items were 0.80 and 0.83 respectively (Table 4). A rule of thumb is that Kappa value 0.70 or above indicates adequate inter-raters agreement. ${ }^{15}$

Validation of scale: Considering psychometric characteristics of the scale- Cronbach's Alpha (ㅁ) = 0.84 , Pearson's correlation $(r)=0.87$ of test-retest, content validity index $(\mathrm{CVI})=0.80$ and multirater Kappa value $=0.83$, we accepted all 24 items and finalized the scale to assess women's autonomy. The sample size of scale construct and validation study was seemed not enough for factor analysis, therefore, we decided to administer the scale along with crosssectional survey for further validation by performing factor analysis.

\section{Further validation of scale}

Factor analysis: We applied principal component analysis method with fixed number of factors three considering the three categories namely decision-making autonomy, movement autonomy and financial autonomy of the preliminary scale. We found KMO and Bertlett's test significant which meant that the set of the observation is adequate for factor analysis. But communalitiesinitial and extraction value of some items was found considerably low $(<0.3)$, cumulative variance of initial Eigenvalues $51.8 \%$ and all items were not loaded on the three factors. As the tested, we again applied the principal component analysis method with extraction of Eigenvalues greater than one, and orthogonal rotation by method Varimax. The analysis showed significant
$\mathrm{KMO}$ and Bertlett's test $(\mathrm{p}<0.001)$, and communalities i.e. initial and extraction values $(>0.3)$ of the total items. The total variance explained that the items were loaded into six factors with Eigenvalues more than one $(>1)$ and cumulative variance of initial Eigenvalues $65 \%$, whereas some items were loaded on more than one factors. We rotated items one by one and checked total items variance and factors loading.

After factor analysis, we decided to remove the item "what food should be cooked?" The remaining items were loaded into five factors with Eigenvalues more than one and cumulative variance of initial Eigenvalues $63.1 \%$. The rotated component matrix (Table 5) showed five factors and single loading by suppressing absolute coefficient value below 0.45 , and Scree plot (Figure 1) also displayed five factors with Eigenvalues greater than one. Factor one consisted of seven items which shows the decision making autonomy, factor two included five items that explains the financial autonomy and factor three comprised of six items which illustrates the movement autonomy. Similarly, factor four and five contained two and three items respectively which show the minor level autonomy on decision making, financial activities and movement freedom of women. Considering the results of factors analysis, we finalized 23 items of the scale and recommended three-point scale (Annex I) for measuring the women's autonomy in the context of developing countries.

Construct validity- convergent and discriminant: Convergent validity explains the association of items within a factor and discriminant validity explains the association of items among factors. We used rotated component matrix (Table 5) to test convergent and discriminant validity of the scale. Each factor has average correlation coefficient value of the loaded items more than 0.6 which indicates good convergent validity of the constructs. Similarly, all 23 items of the scale were loaded clearly in five factors. All five factors have single loading items by suppressing absolute coefficient value less than 0.45 and average coefficient value is more than 0.60 of each factor. It further shows good discriminant validity of the factors. 
Table 5. Rotated component matrix.

Items

Factors

Having baby/another baby

$\begin{array}{lllll}1 & 2 & 3 & 4 & 5\end{array}$

Use of contraceptives

.852

Children's and females' health care and medicine

.843

Inviting and hosting guests

.695

Children's education

.605

Purchase major goods in household such as land, house, computer, TV .593

Being a member of public institutions/organizations

Saving money for your future use

.517

Handle separate bank account

.882

.873

Give money or goods to natal family

.724

Lend/spend money as per personal need and interest

Work outside the house for income

.555

Go marketing/shopping

.787

.767

Go outside the house/compound

.726

Visit to friend/s' house

.641

.624

.473

Go to children's school

Children's clothes and food

Spend money for household affairs

Go to public places/programmes such as temple, church, other religious places, public programmes

Extraction Method: Principal Component Analysis, Rotation Method: Varimax with Kaiser Normalization.

* Rotation converged in 10 iterations

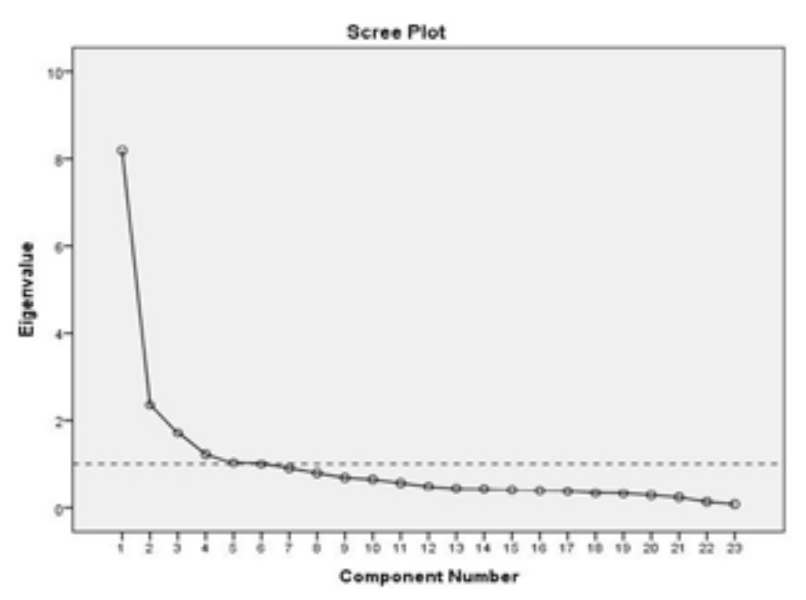

Figure 1. Scree plot

\section{DISCUSSION}

The purpose of this study was to construct and validate a scale for measuring women's autonomy with relevance to Nepal. We developed a three-point Likert-type scale which consists of 23 items. After testing psychometric characteristics of the scale, we concluded that the new scale is a reliable and valid tool for assessing women's autonomy in developing countries.

For assessing the women's autonomy, earlier researchers mainly focused on demographic and socio-economic characteristics of women. Now paradigms have been shifted, modern social researchers emphasize on women's ability to influence in decision-making, control economic and physical resources, movement freedom, reproductive rights and so forth. ${ }^{8,21,22}$ Considering the new paradigms of women's autonomy, we finalized 23 items of the new scale particularly focusing on decision 
Bhandari et al. Construction and Validation of a Women's Autonomy Measurement Scale with Reference to Utilization of Maternal ...

making autonomy, financial autonomy and freedom of movement.

For assuring internal consistency of the scale, most studies used Cronbach's Alpha. ${ }^{21}$ The Cronbach's Alpha values of the scale was above the cutoff point 0.70 and most items of the scale correlated positively. For assessing cross-items consistency, Pearson's correlation (r) 0.6 or above is considered acceptablevalues. ${ }^{23}$ The Pearson's correlation ( $r$ ) 0.87 supports the new scale strongly.

This scale had good face validity, content validity ratio, content validity index and overall agreement among raters- Kappa value. Factor analysis and logistic regression showed good convergent and discriminant validities of the scale. We compared calculated values with other scales and standard statistic values which showed all calculated values were in the acceptable range. Most researchers use correlation, content validity ratio, content validity index and Kappa value for assuring the content validity of the scale. ${ }^{16,23}$

The EFA confirms a smaller number of constructs from a large number of observed items. ${ }^{18}$ For assessing the convergent validity of the scale, we used rotated component matrix wherever all 23 items loaded into five factors with Eigenvalues greater than one by suppressing absolute coefficient value below 0.45 . Each items of five factors had loading value 0.47 or above and the average value of each factors was also above 0.60 , which indicates that the items of the scale have good convergent validity. Similarly, all five factors had single loading items by suppressing small coefficient absolute value less than 0.45 and the Scree plot also displayed five factors with Eigenvalues greater than one. It shows good discriminant validity of the scale. The total items variance, $\mathrm{KMO}$ and Bartlett's test, communalities- initial and extraction, and the coefficient of the loaded items are major determinants for appraising the convergent and discriminant validity of the scale..$^{24,25}$

Construct validity analysis is the best way for validating the new scale. It is a new concept in research whereas researchers compare the outputs of their interest scale with outputs of other any established scales. ${ }^{24}$ We did not find any standard scales for comparison, hence, we tested convergent and discriminant validity of the scale. All five factors of the scale had single loading items by suppressing absolute coefficient value less than 0.45 and average coefficient value more than 0.60 of each factor. Most researchers considered average coefficient value 0.6 or more as cutoff point to assess the convergent validity and suppressing absolute value 0.40 to assess the discriminant validity of the scale. ${ }^{26}$

The study was conducted and further validated into relatively adequate samples and subsamples. Most psychometric tests were applied for assuring the reliability, validity of the scale and validation it. Despite the numbers of strengths, this study was based on the reported information which was obtained from women and to some extent from their husbands and other family members. It covered mainly decision-making autonomy, financial autonomy and freedom of movement out of the bulk of autonomy issues of women in developing countries. We suggest further use and validation of the scale performing confirmatory factors analysis to ensure its measurement capacity of women's autonomy.

\section{CONCLUSIONS}

We have developed three point Likert type measurement scale to bridge the literature gap of standardized tools for appraising women's autonomy in developing countries. It consists of 23-item and covers major three dimensions of women's autonomy i.e. decisionmaking autonomy, freedom for movement and financial autonomy which are most relevant in developing countries. The psychometric characteristics ensured that the scale has good capacity to measure women's autonomy. It furthermore classified the dimensions of women's autonomy into five factors- major and minor groups. We finalize a new scale after confirming the psychometric tests and recommend for further use and validation into large population.

\section{ACKNOWLEDGEMENTS}

We express sincere appreciation to all respondents for their participation in this study. We acknowledge district health offices Rupandehi and Kapilvastu for their kind cooperation and written approval for the study.

\section{Authors' contributions}

VRK and TRB designed study and envisaged the ideas of article. TRB prepared a draft of manuscript and circulated to GD, PSS and VRK for comments. After incorporating the comments, all authors read thoroughly and approved the final manuscript.

\section{Competing interests}

The authors declare no potential conflicts of interest with respect to the research, authorship, and/or publication of this article.

\section{Disclosure}

It's a part of PhD study of first author, which is supported by Pokhara University and University Grants Commission, Nepal. The authors disclose no receipt any of the financial support for the authorship, and/or publication of this article. 
Annex 1. Women's Autonomy Measurement Scale (Likert-type Scale).

Select only one option out of three options given below and write respective number ( 2 or 1 or 0 as applicable) in the given box.

SN Autonomy domains Scale

A. How do you make decision onIndependent Joint

Dependent

(2)

(1)

1 daily household expenditure/purchase?

2 children's clothes and food?

3 children's education?

$4 \quad$ children's and females' health care and medicine?

$5 \quad$ inviting and hosting guests?

6 use of contraceptives?

7 having baby/another baby?

8 purchasing major goods in household such as land, house, computer, TV?

9 being a member of public institutions/organizations?

Total score $=0$ to 18

B. Do you need permission to -

Never

(2)

going outside the house/compound?

going for marketing / shopping?

12 going to hospital/health care facility?

13 going to children's school?

14 visiting to natal family or relative/s' house?

15 visiting friend/s' house?

16 going to public places/programmes such as temple, church, other religious places, public programmes?

Total score $=0$ to 14
Never

(2)

\section{Sometimes Always}

(1)

(0)

\section{Do you need permission to-}

17 work outside the house for income

18 Spend money for household affairs

19 lend/spend money as per personal need and interest

20 saving money for your future use

21 handle separate bank account

22 own and control personal property

23 give money or goods to natal family

Total score $=0$ to 14

Grand total score $=0$ to 46 


\section{REFERENCES}

1. Malhotra A, Schuler SR. Women's empowerment as a variable in international development. Meas Empower Cross-Discip Perspect. 2005;71-88.

2. Matthews Z, Ramasubban R, Rishyasringa B, Stones W. Autonomy and maternal health-seeking among slum populations of Mumbai. Monograph 2003. [cited 2013 Oct 22]; Available from: http:/ / eprints.soton.ac.uk/00008141

3. Allendorf K. Couples' reports of women's autonomy and health-care use in Nepal. Stud Fam Plann. 2007;38(1):35-46.

4. Govindasamy P, Ramesh BM. Maternal education and the utilization of maternal and child health services in India. National family health survey subject reports 1997. [cited 2013 Oct 17]; Available from: http://scholarspace.manoa. hawaii.edu/handle/10125/3472

5. Govindasamy P, Malhotra A. Women's position and family planning in Egypt. Stud Fam Plann. 1996;328-40.

6. Dangal G, Bhandari TR. Women's autonomy: new paradigm in maternal health care utilization. GJMEDPH. 2014;3(5):1-2.

7. Woldemicael G. Do women with higher autonomy seek more maternal and child health-care? Evidence from Ethiopia and Eritrea. Stockholm Research Reports in Demography 2007. [cited 2013 Oct 22]; Available from: http://su.diva-portal. org/smash/record.jsf?pid=diva2:198005

8. Thapa DK, Niehof A. Women's autonomy and husbands' involvement in maternal health care in Nepal. Soc Sci Med. 2013. [cited 2013 Oct 17]; Available from: http://www. sciencedirect.com/science/article/pii/S027795361300333X.

9. Department of Health Services. Annual Report - 2012/13. Kathmandu, Nepal: Ministry of Health and Population, Department of Health Services; 2013.

10. Dean A, Sullivan K, Soe M. OpenEpi: Open Source Epidemiologic Statistics for Public Health, Version. 2015 [cited 2014 May 8]. Available from: http://www.OpenEpi. com.

11. Makinwa-Adebusoye P, Jensen AM. Women's position and demographic change in sub-Saharan Africa, introduction. Women's Position Demogr Change Sub-Sahar Afr. 1995.

12. Jejeebhoy SJ, Sathar ZA. Women's autonomy in India and Pakistan: the influence of religion and region. Popul Dev Rev. 2001;27(4):687-712.

13. Gunasekaran S. Women's autonomy and reproductive behaviour. New Delhi: Gyan Publishing House; 2010.

14. Lambert MJ, Burlingame GM, Umphress V, Hansen NB, Vermeersch DA, Clouse GC, et al. The reliability and validity of the outcome questionnaire. Clin Psychol Psychother. 1996;3(4):249-58.
15. Blankson C, Kalafatis SP. The development and validation of a scale measuring consumer/customer-derived generic typology of positioning strategies. J Mark Manag. 2004;20(1-2):5-43.

16. Randolph JJ. Online Kappa Calculator [Computer software]. 2008. [cited 2014 Nov 13]; Available: http:/ justus.randolph. name/kappa.

17. Worthington RL, Whittaker TA. Scale development research: a content analysis and recommendations for best practices. Couns Psychol. 2006;34:806-38.

18. Brown JD. Choosing the right type of rotation in PCA and EFA: JALT testing \& evaluation. SIG Newsletter. 2009;13(3):20-5

19. Pike GR. The convergent and discriminant validity of NSSE scale-let scores. J. Coll. Stud. Dev. 2006;47(5):550-63.

20. Watson D, Weber K, Assenheimer JS, Clark LA, et al. Testing a tripartite model: evaluating the convergent and discriminant validity of anxiety and depression symptom scales. J. Abnorm. Psychol. 1995;104(1):3-14.

21. Bloom SS, Wypij D, Gupta MD. Dimensions of women's autonomy and the influence on maternal health care utilization in a north Indian city. Demography. 2001;38(1):67-78.

22. Saleem S, Bobak M. Women's autonomy, education and contraception use in Pakistan: a national study. Reprod Health. 2005;2(8):1-8.

23. Silverman WK, Saavedra LM, Pina AA. Test-retest reliability of anxiety symptoms and diagnoses with the anxiety disorders interview schedule for DSM-IV: child and parent versions. J Am Acad Child Adolesc Psychiatry. 2001;40(8):937-44.

24. Watson D, Weber K, Assenheimer JS, Clark LA, Strauss ME, McCormick RA. Testing a tripartite model: I. evaluating the convergent and discriminant validity of anxiety and depression symptom scales. J Abnorm Psychol. 1995;104(1):3-14.

25. Upadhyay UD, Dworkin SL, Weitz TA, Foster DG. Development and validation of a reproductive autonomy scale. Stud Fam Plann. 2014;45(1):19-41.

26. Simpson JA, Gangestad SW. Individual differences in socio-sexuality: evidence for convergent and discriminant validity. J Pers Soc Psychol. 1991;60(6):870-83. 